творческие дела во внеклассной работе, способствующие развитию творческой активности младших школьников.

$$
* * *
$$

1. Ильин Е. П. Психология творчества, креативности, одарённости. СПб: Питер, 2009.

2. Маклаков А. Г. Общая психология. СПб: Питер, 2010.

3. Рыжковская Т. Л. Основы психологии и педагогики. Минск: Изд-во МИУ, 2010.

4. Суворова Г. А. Психология деятельности: Учебное пособие для высших учебных заведений. М.: ПЕР СЭ, 2003.

\title{
Ефремова Д.Н. \\ Современные подходы к разработке программ реабилитации когнитивных функций для людей пожилого возраста в условиях медико-реабилитационного отделения
}

ГБУЗ ПКБ №1 им. Н.А. Алексеева

РГГУ

(Россия, Москва)

doi 10.18411/spc-04-04-2018-16

idsp 000001:spc-04-04-2018-16

\section{Аннотация}

Представлено краткое содержание и результаты апробации комплексной программы восстановления когнитивных функций у людей пожилого возраста. Определение подходов к разработке программ реабилитации когнитивных функций для людей пожилого возраста в условиях медико-реабилитационного отделения задают вектор и сущность новой стратегии комплексной реабилитации. Своевременное осуществление комплексных реабилитационных мероприятий (сочетание лечебного и восстановительного воздействия) в отношении состояния уровня когнитивных функций у людей пожилого возраста, помогает повысить их уровень адаптации и качество жизни, расширить навыки применения полученного информационного и энергетического ресурса для достижения социальной и духовной самореализации.

Ключевые слова: деменция, когнитивные нарушения, синдром мягкого когнитивного снижения, реабилитация, пожилой возраст, синергия, пожилые люди.

\section{Annotation}

Presented summary and results of testing of the complex program of recovery of cognitive functions in the elderly.Analyzed some peculiarities of the dynamics of cognitive sphere in the course of the rehabilitation process. Define approaches to the development of programs of rehabilitation of cognitive functions for the elderly in terms of medical rehabilitation Department set the direction and the essence of the new strategy of complex rehabilitation. Timely implementation of comprehensive rehabilitation measures (combination of therapeutic and restorative effects) in relation to the elderly, helps to increase their level of adaptation and quality of life, improve skills of application of acquired information and energy resource for social and spiritual fulfillment.

Key words: dementia, cognitive impairment, syndrome of mild cognitive impairment, rehabilitation, old age, synergy, the elderly.

В настоящее время в мировой медицинской практике отмечается тенденция к интеграции различных оздоровительных и реабилитационных систем. Актуальность проблемы обусловлена задачами совершенствования комплексных (терапии и немедикаментозных технологий) методов восстановления и укрепления когнитивной сферы пожилого человека путем расширения адаптационных возможностей организма. 
Когнитивные нарушения выявляются примерно у 25\% людей пожилого возраста, в том числе у 6-8\% - диагностируется деменция, а у 16-19\%-умеренные когнитивные нарушения. Падение работоспособности, быстрая утомляемость, эмоциональная неустойчивость и истощаемость нервно-психических процессов как проявления старческой астении, в большинстве случаев приводят к снижению адаптивных возможностей к актуальным жизненным условиям и соответственно, понижению качества жизни [8].

В Международной классификации болезней 10-го пересмотра (МКБ-10) используется термин «легкое когнитивное расстройство» (F06.7). В отечественной литературе англоязычный термин «mildcognitiveimpairment» (MCI) перевести как «мягкое когнитивное снижение». Нарушение, характеризующееся снижением памяти, трудностью обучения, сниженной способностью концентрироваться на выполнении какой-либо задачи на длительное время. Часто имеет место выраженное ощущение психической усталости при попытке решить умственную задачу; обучение новому представляется субъективно трудным, даже когда объективно оно успешно $[3,4]$.

Наиболее эффективной мерой по предупреждению дальнейшего прогрессирования заболевания, особенно на раннем этапе его развития, является, согласно современным воззрениям обязательное включение в систему реабилитации немедикаментозных технологий.

Опора на современные подходы при разработке программы реабилитации когнитивной сферы при мягком когнитивном снижении и применение принципа управления сложноорганизованными системами позволило аккумулировать разрозненные психологические, нейропсихологические, психотерапевтические тренинги, медикаментозное сопровождение и режим пребывания в условиях отделения дневного пребывания в единый комплекс.

Результатом применения принципа синергетики является наличие в системе реализации реабилитационной программы ряда факторов (технологий, методик), повышающих осознанность самим пациентом процессов, которым подвержен его организм - соматическом, психо-эмоциональном, физическом уровнях. Суммирующий эффект взаимодействия двух или более факторов, характеризующийся тем, что их действие существенно превосходит эффект каждого отдельного компонента в виде их простой суммы (в нашем случае, например присоединение психотерапевтических тренингов к нейропсихологическим, тренингам по адаптивной физической культуре и т.д.)

Апробация реабилитационной Программы проходила на базе ГБУЗ ПКБ№1 в 2016-2017г.г. Курс реабилитации в течении шести недель, проходят пациенты среднего, пожилого и старческого возраста (по периодизации ВОЗ) с жалобами на снижение памяти, существенно влияющее на ухудшение их качества жизни.

C участниками реабилитационной Программы проводится первичное собеседование с врачом, медицинские психологи проводят индивидуальное патопсихологическое исследование и мотивационную беседу, по выделению индивидуально значимых целей и «мишеней» реабилитационного воздействия.

Группы участников реабилитационного процесса формируются с учетом возрастных, когнитивных, поведенческих особенностей личности.

Цель реабилитационной Программы: предупреждение распада/восстановление когнитивных функций. Повышение способности у людей пожилого возраста, с мягким когнитивным снижением, восприятия новой информации, структурирование иерархии потребностей и мотивов взаимодействия с окружающим социумом.

В Программу реабилитации когнитивных (интеллектуальных) функций составили специально адаптированные психологические, психотерапевтические блоки, учитывающие нейропсихологические принципы системной динамической организации 
головного мозга, возрастные особенности здоровья и личности пожилого человека с мягким когнитивным снижением.

Исходя из целей реабилитационной программы, и поведенного патопсихологического исследования выделены центральные задачи восстановления когнитивных функций, разработаны соответствующие технологии (модифицированы известные тренинги) и рассчитано время, необходимое и достаточное, для решения поставленной конкретной задачи.

Каждый тренинг Программы реабилитации состоит из 6-10 занятий (занятие длится 50 - 60 минут). Все составляющие программы проводятся согласно утвержденному расписанию, в групповом режиме. Группы закрытые. Наполняемость группы 8-10 человек. Для каждой группы составляется расписание на рабочую неделю, с указанием времени, названия тренинга, кабинета и фамилия специалиста, который проводит указанный тренинг. В таблице представлен макет расписания на одну группу.

Таблица 1

Макет расписания для одной группы участников

\begin{tabular}{|c|c|c|c|c|c|}
\hline \multirow{4}{*}{ 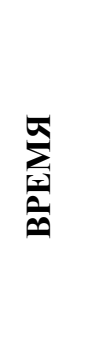 } & \multicolumn{5}{|c|}{ Типовое расписание для одной группы } \\
\hline & дата & дата & дата & дата & дата \\
\hline & Понедельник & Вторник & Среда & Четверг & Пятница \\
\hline & \multicolumn{5}{|c|}{ Группа № } \\
\hline $\begin{array}{l}1 \\
\oplus \\
\infty \\
\infty\end{array}$ & \multicolumn{5}{|c|}{$\begin{array}{c}\text { Прием пациентов, } \\
\text { Беседа с врачами, процедуры, консультации врачей-специалистов. }\end{array}$} \\
\hline 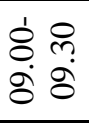 & $\begin{array}{c}\text { АФК } \\
\text { тренирующий } \\
\text { режим } \\
\end{array}$ & $\begin{array}{c}\text { АФК } \\
\text { щадящий } \\
\text { режим } \\
\end{array}$ & $\begin{array}{l}\text { АФК тренирующий } \\
\text { режим }\end{array}$ & $\begin{array}{c}\text { АФК } \\
\text { щадящий режим }\end{array}$ & $\begin{array}{l}\text { АФК тренирующий } \\
\text { режим }\end{array}$ \\
\hline $\begin{array}{l}1 \\
\varrho\end{array}$ & $\begin{array}{c}\text { Тренинг } \\
\text { высших } \\
\text { психических } \\
\text { функций } \\
\end{array}$ & $\begin{array}{l}\text { Арт-когнитивный } \\
\text { тренинг }\end{array}$ & $\begin{array}{l}\text { Нейрокогнитив- } \\
\text { ный тренинг }\end{array}$ & $\begin{array}{c}\text { Тренинг высших } \\
\text { психических } \\
\text { функций }\end{array}$ & $\begin{array}{l}\text { Нейрокогнитив- } \\
\text { ный Тренинг }\end{array}$ \\
\hline $\begin{array}{l}1 \\
8 \\
8 \\
= \\
=\end{array}$ & \multicolumn{5}{|c|}{$\begin{array}{c}\text { Тренинг социальных и коммуникативных навыков, Тренинг навыков запоминания и } \\
\text { воспроизведения информации, Тренинг мелкой моторики, пространственного праксиса, Тренинг } \\
\text { тренировки концентрации внимания } \\
\end{array}$} \\
\hline 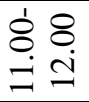 & \multicolumn{5}{|c|}{$\begin{array}{c}\text { Медицинские процедуры, индивидуальные занятия с инструктором по адаптивной физической } \\
\text { культуре (АФК) }\end{array}$} \\
\hline 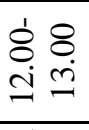 & $\begin{array}{l}\text { Психо } \\
\text { образование }\end{array}$ & $\begin{array}{l}\text { Ресурс-ориентиро } \\
\text { ванный тренинг }\end{array}$ & $\begin{array}{c}\text { Телесно } \\
\text { ориентированная } \\
\text { терапия } \\
\end{array}$ & $\begin{array}{c}\text { Ресурс- } \\
\text { ориентирован } \\
\text { ный тренинг } \\
\end{array}$ & $\begin{array}{c}\text { Телесно } \\
\text { Ориентирован } \\
\text { ная терапия } \\
\end{array}$ \\
\hline 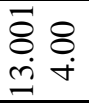 & \multicolumn{5}{|c|}{ Обед } \\
\hline 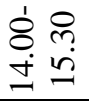 & \multicolumn{5}{|c|}{ Беседа с врачами, процедуры, консультации врачей-специалистов. } \\
\hline 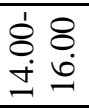 & \multicolumn{5}{|c|}{ Индивидуальные консультации с врачом психотерапевтом, медицинскими психологами } \\
\hline$\underset{8}{8}$ & \multicolumn{5}{|c|}{ Завершение дня } \\
\hline
\end{tabular}

В первую (установочную) неделю пациенты, прошедшие процедуру приема, после знакомства с правилами распорядка в отделении, участвуют в информационнопрактическом тренинге «Психообразование для пожилых людей». Это цикл из шести 
лекций, который, по нашему мнению, способствует в доступной для пожилых людей форме, расширению представлений о причинах нарушения и методах восстановления памяти. В доступной форме (учебный фильм о работе мозга) пациентов информируют о современных методах поддержания памяти (медикаментозных, нейропсихологических и социально-практических). Формируют научное представление о воздействии медикаментозных препаратов на укрепление памяти.

По нашему мнению, расширение представлений о работе головного мозга, о тесной взаимосвязи процессов памяти с другими психическими процессами позволяет задать участникам вектор-мотивацию на целенаправленное участие в программе, что позволяет каждому пациенту совершить собственный мотивационный выбор (буквально пройти точку бифуркации, если оперировать терминами синергии).

К завершению первой недели, по мере формирования групп, для каждой группы, проводится Коммуникативный тренинг. Участников реабилитационной программы знакомят с правилами работы реабилитационной группы, правилами поддержания системы безопасного общения. В ходе тренинга закладываются навыки бесконфликтного общения с окружающими (в социуме). Пациенты обучаются стратегиям совладающего поведения при сложных (трудных) жизненных ситуациях.

Начиная со второй по пятую неделю, пациенты активно включены в медикореабилитационный процесс. Перед началом занятий все пациенты, беседуют с лечащим врачом, выполняют назначенные процедуры.

Ежедневно, с участниками, проводятся занятия Адаптивной физической культурой, для каждой группы общее время составляет 20-30 минут. Группы по АФК формируются в соответствии с уровнем состояния физической активности и выносливости (шкала Бартела). Занятия по АФК организованы в соответствии с требованиями проведения комплексов щадяще-тренирующего и щадящего режима.

Первое занятие посвящено обучению пациентов подсчету пульса, который на протяжении всего цикла реабилитации фиксируется в начале каждой тренировки, и по ее завершению. Комплекс адаптивной тренировки составлен из дыхательных, силовых упражнений и упражнений на растяжку и равновесие (баланс). Все упражнение проводятся в положении сидя или стоя.

В течение всего курса реабилитации, каждый участник программы участвует в таких тренингах, как:

Тренинге концентрации внимания (один час в неделю.Всего 6 часов), который способствует расширению полей зрения, удержанию, переключения и концентрации внимания.

Тренинг социальных и бытовых навыков (один час в неделю.Всего 6 часов) формирует навык позитивных стереотипов действий, умения противостояния мошенникам, манипуляторам. Участники разрабатывают для себя индивидуальный режим дня, уделяя особое внимание соотношение времени бодрствования и отдыха. Получают навыки формирования краткосрочных и долгосрочных планов и целей дальнейшей жизни.

Тренинг навыков воспроизведения информации (два часа в неделю.Всего 12 часов) - формирование навыков произвольного запоминания и воспроизведения информации (визуальной, аудиальной).

Тренинг мелкой моторики и пространственного восприятия и праксиса (один час в неделю.Всего 6 часов) - активизация гнозиса, пространственного и квазипространственного восприятия, праксиса, мелкой моторики. 
Нейрокогнитивный тренинг - комплекс занятий, способствующий активизации локальных центров головного мозга обеспечивающих нейроорганизацию восстанавливаемой способности.

Тренинг высших психических функций - комплекс занятий, обеспечивающий интеграцию локальных процессов в целостную психическую функцию (память, мышление, внимание).

Арт-когнитивный тренинг - нормализация совместной работы правого и левого полушарий головного мозга, активизация интеллектуального потенциала. Специальным образом организованные занятия способствуют оптимальному восприятию сложной информации, с ее последующей интеллектуальной проработкой для выбора и принятия оптимального решения при переживании деструктивных эмоций.

Ресурс-ориентированная психотерапия - восстановление общего энергетического потенциала, снижение уровня деструктивных эмоциональных состояний (страх, тревога, гнев, обида), структурирование иерархии ценностей и потребностей личности для сохранения интеллектуальной активности и психического (эмоционального) здоровья.

Телесно-ориентированная психотерапия- формирование навыка снижения остроты дискомфортных эмоциональных переживаний. Обучение восприятию переживаемых эмоций. Восстановление энергетического потенциала.

На заключительнойю (шестой) неделе процесса реабилитации проводится повторное психологическое исследование состояния когнитивных функций.

А так же тренинги, направленные на повышение стрессоустойчивости личности, позволяющие встроить полученные навыки в собственную жизнь. Дополнительно проводятся специальные занятия, расширяющие представления пациентов о собственных возможностях с помощью таких психотерапевтических техник, как терапия творческим самовыражением и когнитивная психодрама.

Терапия творческим самовыражением - направлена на актуализацию способностей выражения переживаемых эмоций и идей, осведомленности об окружающем мире, способах взаимодействия с окружающими людьми посредством написания собственных рассказов (стихотворений), фотографий, рисунков и пр. Когнитивная психодрама-расширяет поведенческий репертуар личности, ее навыки снижения остроты переживаний сложных отношений с окружающими, раскрывает творческие способности для достижения поставленных целей, позволяет примириться с прошлым.

Таким образом, сущность новой стратегии формирования реабилитационного цикла для людей пожилого возраста с мягким когнитивным снижением (Программы реабилитации) - в выборе соответствующих подходов и технологий, которые усиливают эндогенные восстановительные процессы (по принципу синергии), содействуют активизации пластичности структур мозга.

\section{Выводы}

1. Пребывание пациента в условиях напряженного влияния организованного реабилитационного процесса требует адекватных физиологических ответов, одним из которых является повышение уровня психосоматической устойчивости к нагрузкам. Это проявилось, со слов участников реабилитационной программы, уменьшением эпизодов головной боли, головокружений, снижением эмоциональной лабильности и нарушений сна.

2. Параллельно субъективным изменениям диагностировано уменьшение объективных проявлений соматической симптоматики во время прохождения курса 
реабилитации когнитивных функций и объективное, подтвержденное анализом результатов участников улучшением памяти.

3. Разработанная программа реабилитации когнитивных функций

4. опирается на фундаментальные принципы нейропсихологического восстановительного обучения и современные подходы, разработанные в области восстановительной медицины.

5. В заданные поведенческие алгоритмы реабилитационного процесса

6. целесообразно интегрировать упражнения, ориентированные на оптимизацию произвольной саморегуляции, энергетики сенсомоторных взаимодействий, операциональных составляющих высших психических процессов.

7. Принцип синергетического воздействия, в процессе реабилитации

8. когнитивных функций людей пожилого возраста способствует активизации резервов психосоматической саморегуляци.

\section{Заключение}

Своевременное осуществление комплексных реабилитационных мероприятий (сочетание лечебного и восстановительного воздействия) в отношении людей пожилого возраста, повышает уровень адаптации и качество жизни, расширяет навыки применения полученного информационного и энергетического ресурса для достижения социальной и духовной самореализации.

Определение подходов к разработке программ реабилитации когнитивных функций для людей пожилого возраста в условиях медико-реабилитационного отделения задают вектор и сущность новой стратегии комплексной реабилитации.

Применяемые в реабилитационной Программе подходы определили выбор средств и технологий, которые усиливают эндогенные восстановительные процессы, содействуют активизации пластичности структур мозга.

$$
* * *
$$

1. Авербух Е.С. Неврозы и неврозоподобные состояния в позднем возрасте. Л. 1976

2. Анцыферова Л.И. Психология старости: особенности развития личности в период поздней взрослости. //Психол. Журнал. Том 22 №3. 2001.

3. Гаврилова С.И. Деменция // Руководство по гериатрической психиатрии / Под ред. С.И.Гавриловой. М.: Пульс, 2014. С. 23-145.

4. Гаврилова С.И., Калын Я.Б. Социально-средовые факторы и состояние психического здоровья пожилого населения (клинико-эпидемиологическое исследование) // Вестник РАМН. 2002. Т. 9. С. 15-20.

5. Гехт И.А. Организация методико-социальной помощи пожилым и старым людям // Проблемы социальной гигиены. 2001.

6. Губачев Д.М., Макиенко В.В. Гериатрические проблемы семейной медицины. СПб. 2000 .

7. Ефремова Д. Н. Психологическая реабилитация людей пожилого возраста // Евразийский союз ученых. 2016. № 1-4. С. 130-133.

8. Королькова Т.Н. Современные теории старения человека: Обзор: //Вестник дерматологии и венерологии. 2001.

9. Краснова О.В. Теоретические вопросы подготовки людей к выходу на пенсию. // Психология зрелости и старения №4(12). 2000.

10. Полищук Ю.И. Баранская И.В. Разрушение высших личностных смыслов как важный фактор развития невротических расстройств в позднем возрасте. //Клиническая геронтология. 2001. №5. c.17-21.

11. Практическая психодиагностика. Методики и тесты.под ред. Райгородского Д.Я. Учебное пособие.- Самара: Издательский Дом «Бахрах-М»,2011.- 672 с.

12. Gao X., Deng-Bryant Y., Cho W. et al. Selective death of newborn neurons in hippocampal dentate gurus following moderate experimental traumatic brain injury // J. Neurosci Res. - 2008. - Vol. 86. - № 10. P. 2258-2270.

13. Rapoport M., Wolf U., Herrmann N. et al Traumatic brain injury, Apolipoprotein E-epsilon4, and cognition in older adults: a two-year longitudinal study // J. Neuropsychiatry Clin. Neurosc. - 2008. Vol. 20. - №1. - P. 68-73.

14. Talassi E. et al. Effectiveness of a cognitive rehabilitation program in mild dementia (MD) and mild cognitive impairment (MCI): a case control study // Arch. Gerontol. Geriatrics. 2007. Vol. 44. C. 391399. 